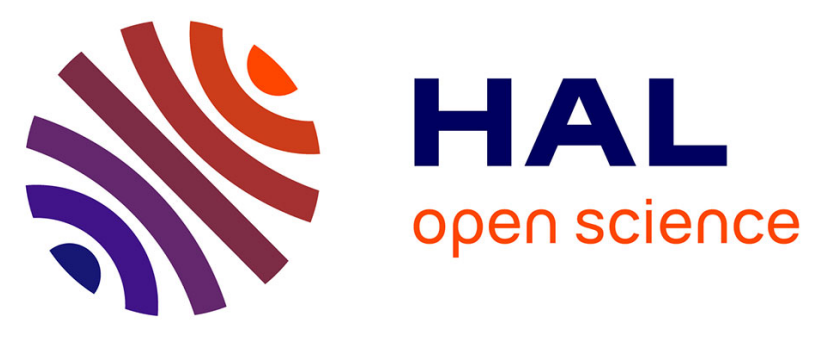

\title{
On the use of adenovirus dodecahedron as a carrier for glycoconjugate vaccines
}

\author{
Maruthi Prasanna, Malgorzata Podsiadla-Bialoskorska, Damian Mielecki, \\ Nicolas Ruffier, Amina Fateh, Annie Lambert, Mathieu Fanuel, Emilie \\ Camberlein, Ewa Szolajska, Cyrille Grandjean
}

\section{To cite this version:}

Maruthi Prasanna, Malgorzata Podsiadla-Bialoskorska, Damian Mielecki, Nicolas Ruffier, Amina Fateh, et al.. On the use of adenovirus dodecahedron as a carrier for glycoconjugate vaccines. Glycoconjugate Journal, 2021, 38 (4), pp.437-446. 10.1007/s10719-021-09999-3 . hal-03313331

\section{HAL Id: hal-03313331 \\ https://hal.science/hal-03313331}

Submitted on 3 Aug 2021

HAL is a multi-disciplinary open access archive for the deposit and dissemination of scientific research documents, whether they are published or not. The documents may come from teaching and research institutions in France or abroad, or from public or private research centers.
L'archive ouverte pluridisciplinaire HAL, est destinée au dépôt et à la diffusion de documents scientifiques de niveau recherche, publiés ou non, émanant des établissements d'enseignement et de recherche français ou étrangers, des laboratoires publics ou privés. 


\section{On the use of adenovirus dodecahedron as a carrier for glycoconjugate}

\section{2 vaccines}

3 Maruthi Prasanna, ${ }^{1}$ Malgorzata Podsiadla-Bialoskorska, ${ }^{2}$ Damian Mielecki, ${ }^{2}$ Nicolas Ruffier, ${ }^{1,2}$ Amina Fateh, ${ }^{1}$

4 Annie Lambert, ${ }^{1}$ Mathieu Fanuel, ${ }^{3,4}$ Emilie Camberlein, ${ }^{1}$ Ewa Szolajska, ${ }^{2}$ Cyrille Grandjean ${ }^{1}$

$5 \quad$ cyrille.grandjean@univ-nantes.fr ORCID 0000-0002-9775-6917

$6{ }^{1}$ Université de Nantes, CNRS, Unité Fonctionnalité et Ingénierie des Protéines (UFIP), UMR 6286, F-44000

$7 \quad$ Nantes, France

$8{ }^{2}$ Institute of Biochemistry and Biophysics, Polish Academy of Sciences, Pawinskiego 5a, 02-106 Warszawa,

9 Poland

${ }^{3}$ INRAE, UR BIA, F-44316 Nantes, France

${ }^{4}$ INRAE, BIBS facility, F-44316 Nantes, France

\section{Abstract}

Virus-Like Particles (VLPs) have been used as immunogenic molecules in numerous recombinant vaccines.

VLPs can also serve as vaccine platform to exogenous antigens, usually peptides incorporated within the protein sequences which compose the VLPs or conjugated to them. We herein described the conjugation of a synthetic tetrasaccharide mimicking the Streptococcus pneumoniae serotype 14 capsular polysaccharide to recombinant adenoviral type 3 dodecahedron, formed by the self-assembling of twelve penton bases and investigated the induced immune response when administered subcutaneously (s.c.). Whether formulated in the form of a dodecahedron or disassembled, the glycoconjugate induced an anti-protein response after two and three immunizations equivalent to that observed when the native dodecahedron was administered. On the other hand, the glycoconjugate induced a weak anti-IgM response which diminishes after two doses but no $\operatorname{IgM-to-\operatorname {IgG}}$ switch was observed in mice against the serotype 14 capsular polysaccharide. In definitive, the whole conjugation process preserved both particulate nature and immunogenicity of the adenoviral dodecahedron. Further studies are needed to fully exploit adenoviral dodecahedron potential in terms of plasticity towards sequence engineering and of its capacity to stimulate the immune system via the intranasal route of administration as well as to shift the response to the carbohydrate antigen by playing both with the carbohydrate to protein ratio and the length of the synthetic carbohydrate antigen.

Keywords Glycoconjugate vaccine, carbohydrate antigen, virus-like particle, adenovirus dodecahedron,

Streptococcus pneumoniae 


\section{Introduction}

Polysaccharides as expressed at bacterial cell surfaces have been for long time recognized as potential targets for humoral responses [1]. This has led to the advent of the polysaccharide vaccines and latter, to that of glycoconjugate vaccines [2]. Glycoconjugate vaccines consist in the covalent linking of a carbohydrate antigen to a protein. The protein referred to as carrier protein elicits a T-cell help which eventually evokes a carbohydrate-specific memory response [3]. Although the carrier protein is essential in mounting the immune response, it often appears as the neglected valency in comparison with the carbohydrate antigen [4],[5]. Only a handful number of proteins have been approved for use as carriers in humans, typically bacterial toxoids such as tetanus toxoid $(150 \mathrm{kDa})$, diphtheria toxoid or $\mathrm{CRM}_{197}(62 \mathrm{kDa})$ and Haemophilus protein D $(42 \mathrm{kDa})$ or the outer membrane protein complex of serogroup B meningococcus (OMPC) (36kDa). Using proteins from a pathogen playing the dual role of carrier as well as protective antigen has been envisaged to simplify multicomponent vaccine formulations and to reduce cost associated with the development of a new carrier [6],[7]. However, such strategy may result in suboptimal response due to carbohydrate and protein B cell epitope competition for restricted T cell help [8],[9], an issue which mitigates its scope. To satisfy the need for novel carriers, we have therefore thought to rely on VLPs as both an alternative and an attractive strategy. VLPs are self-assembled structural viral proteins forming nanoparticles. Particulate systems are inherently more immunogenic than soluble systems as nano- and microparticles mimics the size, geometry and properties that the immune system recognizes [10]. In a way VLPs are very similar to live viruses since they can drain freely into the lymphatic vessels, be taken up efficiently by the antigen-presenting cells and induce a strong immune response but they are not infectious. Thanks to these properties several VLP-based vaccines have been licensed for the prevention of viral diseases such as those caused by hepatitis B virus or papillomavirus [11],[12]. In addition, VLPs tolerate genetic or chemical conjugation to give rise to multivalent nanoplatform for exogenous antigen delivery [12]. VLPs engineered with exogenous antigens are usually more immunogenic than the antigen itself as they present a dense array of antigens which efficiently crosslinks B cell receptors thank to the VLPs' highly repetitive and symmetrical nature [13],[14]. These unique features combined with their protein nature suitable to support a T cell help design VLP as appealing platforms for glycoconjugate vaccines. However, few examples which make use of a VLP as a carrier for carbohydrate antigen have been reported. Hence tumor-associated carbohydrate antigen Tn [15], oligomannosides [16] or two synthetic tetrasaccharides representing one or two repeating units of the polysaccharide capsules of Streptococcus pneumoniae serotype 14 or 3, respectively,[17] have been chemically attached to the isodecahedral capsid of bacteriophage $\mathrm{Q} \beta$. All resulting glycoconjugates induced an 
antibody response against the carbohydrate antigen. Of note, the pneumococcal glycoconjugate vaccines involved glycopeptide-specific T cells and were protective in a passive infectious model in mice [17]. Keeping $S$. pneumoniae as a model, we decided to investigate the human adenoviral type 3 dodecahedron (Dd) as a VLPbased glycovaccine platform for its formidable capacity to infect human cells. Indeed, Dd is composed of twelve pentameric penton bases, responsible for adenovirus cell penetration at an extent of 200,000 to $300,000 \mathrm{Dd} / \mathrm{cell}$ in culture [18]. Such penetration efficiency is explain by the presence of an RGD motif within a loop which favors its interaction with integrin receptor expressed at the target cell surfaces. In addition, Dd recognizes heparan sulfate proteoglycans expressed on mammalian cells surfaces which form a second entry door [19],[20]. It has successfully been engineered to provide chimeric influenza [21],[22] or Chikungunya vaccines [23] meaning that it can be used as a vaccine platform but its use as carbohydrate antigen carrier remains unprecedented.

\section{Material and methods}

\section{Reagents}

Anhydrous solvents $\mathrm{CH}_{2} \mathrm{Cl}_{2}$, EtOH and $\mathrm{MeOH}$ were purchased from Acros Organics. Anhydrous sodium sulfate, sodium borohydride, boric acid and sulfuric acid were from VWR, nickel (II) chloride $\left(\mathrm{NiCl}_{2} \cdot 6 \mathrm{H}_{2} \mathrm{O}\right)$ was from Acros Organics, $25 \%$ sodium methoxide solution in $\mathrm{MeOH}$, ethylene diamine, glutaraldehyde ( $25 \%$ in $\left.\mathrm{H}_{2} \mathrm{O}\right)$, amberlite IR120( $\left.\mathrm{H}^{+}\right)$and anthrone were purchased from Sigma-Aldrich.

\section{Expression and purification of Dd}

Dd was expressed in FlashBacGold (Oxford Expression Technologies) baculovirus expression system following the manufacturer's protocol. Virus stocks were prepared by infection of Spodoptera frugiparda 21 monolayer. For Dd expression, Trichoplusia ni (HighFive) cells $\left(2 \times 10^{6}\right.$ cells $\left./ \mathrm{ml}\right)$ grown in suspension were infected with the recombinant baculovirus at multiplicity of infection 4 and cultured for $48 \mathrm{~h}$. Expressing cells were lysed and Dd was purified from the supernatant by size exclusion chromatography followed by anion exchange chromatography, as described previously [24]. Dd preparation was concentrated using Amicon Ultra concentrators (Merck Millipore), protein concentration was determined by NanoDrop ND-200 UV-Vis Spectrophotometer (Thermo Scientific). The homogeneity of preparations were analyzed by SDS-PAGE 12\%. The assembly status of purified Dd was analyzed by electron microscopy.

\section{Tetrasaccharide synthesis (Pn14TS)}

To a solution of known 2-azidoethyl (2,3,4,6-tetra- $O$-acetyl- $\beta$-D-galactopyranosyl)-(1 $\rightarrow 4)$-(2,3,6-tri-O-acetyl- $\beta$ D-galactopyranosyl)-( $1 \rightarrow 6)$-[(2,3,4,6-tetra- $O$-benzoyl- $\beta$-D-galactopyranosyl)-( $1 \rightarrow 4)]$-2-deoxy-2-phtalimido- $\beta$-D- 
glucopyranoside [25] $(29.6 \mathrm{mg}, 0.023 \mathrm{mmol})$ in a mixture of $\mathrm{CH}_{2} \mathrm{Cl}_{2} / \mathrm{EtOH}(1.69: 0.36 \mathrm{~mL})$ were successively added $\mathrm{NaBH}_{4}\left(1.84 \mathrm{mg}, 2.1\right.$ equiv) and a catalytic amount of $\mathrm{NiCl}_{2} \cdot 6 \mathrm{H}_{2} \mathrm{O}$ at room temperature. The reaction mixture was stirred for $1 \mathrm{~h}$ and then concentrated under reduced pressure. The crude residue was diluted in $\mathrm{CH}_{2} \mathrm{Cl}_{2}$ and washed with $\mathrm{H}_{2} \mathrm{O}$ (twice) and brine. The organic layer was dried over $\mathrm{Na}_{2} \mathrm{SO}_{4}$, filtered and concentrated under reduced pressure to afford a peracetylated intermediate. To a solution of this intermediate (29 $\mathrm{mg})$ in $\mathrm{MeOH}$ were added ethylene diamine (18 $\mu \mathrm{L}, 12$ equiv) and MeONa in 25\% solution in $\mathrm{MeOH}(10 \mu \mathrm{L})$. The reaction mixture was stirred for 3 hour at room temperature, neutralized to $\mathrm{pH} 7$ (paper) using Amberlite IR120 $\left(\mathrm{H}^{+}\right)$, filtered and concentrated under reduced pressure to provide 2-aminoethyl ( $\beta$-D-galactopyranosyl)$(1 \rightarrow 4)$-( $\beta$-D-galactopyranosyl)-( $1 \rightarrow 6)$-[( $\beta$-D-galactopyranosyl)-( $1 \rightarrow 4)]-2$-deoxy-2-acetamido- $\beta$-Dglucopyranoside (Pn14TS) (17 mg, quantitative); HR-ESI-MS: $m / z$ Calcd for $\mathrm{C}_{28} \mathrm{H}_{50} \mathrm{~N}_{2} \mathrm{O}_{21}[\mathrm{M}+\mathrm{H}]+751.2984$, found 751.2949 .

\section{Conjugate Synthesis}

In a typical experiment, to a solution of Pn14TS $(100 \mu \mathrm{g})$ in $100 \mu \mathrm{l}$ of borate buffer $(0.1 \mathrm{M}$ sodium borate, 150 $\mathrm{mM} \mathrm{NaCl}, \mathrm{pH}$ 9.6) was added $30 \mu \mathrm{l}$ of glutaraldehyde ( $25 \%$ solution in $\mathrm{H}_{2} \mathrm{O}$ ), then the solution is stirred for 4 min at $4{ }^{\circ} \mathrm{C}$. Next, $1 \mathrm{ml}$ of Dd solution at $1 \mathrm{mg} / \mathrm{ml}$ in $20 \mathrm{mM}$ HEPES buffer (containing EDTA $2 \mathrm{mM}, \mathrm{NaCl}$ $150 \mathrm{mM} \mathrm{pH} 7.5)$ is added, and the reaction mixture is further stirred for 1 hour at $4{ }^{\circ} \mathrm{C}$. Finally, $\mathrm{NaBH}_{4}(450 \mu \mathrm{g})$ is added and the reaction mixture stirred for $15 \mathrm{~min}$ at $4{ }^{\circ} \mathrm{C}$. The solution was then dialyzed against $20 \mathrm{mM}$ Tris, pH 7.5, containing 2 mM EDTA, 5\% glycerol using Pierce Slide-A-Lyzer cassette (molecular weight cutoff, $20 \mathrm{~K}$ ) and stored at $4{ }_{-}^{\circ} \mathrm{C}$. Bradford assay (BioRad protein assay) was used to determine the concentration of the protein. The anthrone/sulphuric acid method [26] was used for the quantification of the sugar content using Pn14TS as a standard, as described previously [27]. The carbohydrate antigen protein ratio was determined by mass spectrometry.

\section{Mass spectrometry}

High-resolution mass spectrum was recorded in positive mode on Waters SYNAPT G2-Si HDMS with detection with a hybrid quadrupole time of flight (Q-TOF) detector. The compounds was dissolved in $\mathrm{MeOH}$ at a concentration of $1 \mathrm{mg} / \mathrm{ml}$ and then infused into the electrospray ion source at a flow rate of $10 \mu \mathrm{l} \cdot \mathrm{min}-1$ at 100 ${ }^{\circ} \mathrm{C}$. The mass spectrometer was operated at $3 \mathrm{kV}$ while scanning the magnet at a typical range of 4000-100 Da. The mass spectrum was collected as continuum profile data. An accurate mass measurement was achieved based on every five-second auto-calibration using leucine-enkephalin $\left([\mathrm{M}+\mathrm{H}]^{+}=556.2771 \mathrm{~m} / \mathrm{z}\right)$ as an internal standard. 
The samples were analyzed by matrix-assisted laser desorption/ionization (MALDI)-time-of-flight (TOF) MS. A sinapinic acid solution at $10 \mathrm{mg} \cdot \mathrm{mL}^{-1}$ in $\mathrm{H}_{2} \mathrm{O}-\mathrm{CH}_{3} \mathrm{CN}-\mathrm{TFA}$ (50:50:0.3) was used as the MALDI matrix. The samples $(75 \mathrm{pmol}$ in $1 \mu \mathrm{L})$ were deposited and then covered by the matrix $(1 \mu \mathrm{L})$ on a polished steel MALDI target plate. MALDI measurements were then performed on a rapifleX MALDI-TOF spectrometer (Bruker Daltonics, Bremen, Germany) equipped with a Smartbeam 3D laser $(355 \mathrm{~nm}, 10000 \mathrm{~Hz})$ and controlled using the Flex Control 4.0 software package. The mass spectrometer was operated with positive polarity in linear mode. Spectra were acquired in the range of $15000-100000 \mathrm{~m} / \mathrm{z}$. The mass spectrometer was calibrated between $20 \mathrm{kDa}$ and $70 \mathrm{kDa}$ with the Protein Standard II (Bruker Daltonics, Bremen, Germany).

\section{Electron microscopy}

Negative Stain Mica-carbon Flotation Technique (MFT) was applied. Samples were absorbed to the clean side of a carbon film on mica, stained and transferred to a 400-mesh copper grid. The images were taken under low dose conditions $\left(<10 \mathrm{e}^{-/ \AA^{2}}\right)$ with defocus values between 1.2 and $2.5 \mu \mathrm{m}$ on a Tecnai 12 LaB6 electron microscope at $120 \mathrm{kV}$ accelerating voltage using CCD Camera Gatan Orius 1000.

\section{Immunization}

The Dd and Pn14TS-Dd formulations were dialyzed against 10 mM PBS using Pierce Slide-A-Lyzer cassette (molecular weight cutoff, 10K). One batch of Pn14-Dd was freeze-dried in absence of cryo-protectant and then reconstituted with $\mathrm{H}_{2} \mathrm{O}$. Actual concentration in protein of every formulation was about $400 \mu \mathrm{g} / \mathrm{mL}$. The assembly status of the different formulation was analyzed by electron microscopy.

Groups of 5 male C57/BL6J (5 week old) mice were injected s.c. with PBS, Dd (64 $\mu$ g protein/dose), Pn14TSDd conjugate or disassembled Pn14TS-Dd conjugate (64 $\mu$ g protein/dose-1.9 $\mu$ g tetrasaccharide/dose) diluted with $160 \mu \mathrm{L}$ of RIBI adjuvant (Sigma) in PBS. The mice were immunized at day 0,14 , and 28 . The sera were collected on days 21 and 35 . Sera were stored at $-80{ }^{\circ} \mathrm{C}$.

\section{ELISA}

The $\mathrm{Ab}$ responses induced upon immunizations were assessed 1 week after the second and the third injections by ELISA. Dd and capsular polysaccharide serotype 14 (CP14) (Alliance Bio Expertise), were used as coated antigens to define the anti-Dd or anti-CP14 Ab titers. Dd (0.1 $\mu \mathrm{g} / \mathrm{well})$ in $10 \mathrm{mM}$ PBS, pH 7.3 (100 $\mu \mathrm{L} /$ well), was coated on 96 wells microtiter plates Nunc Maxisorp (ThermoFisher Scientific) plates overnight at $4{ }^{\circ} \mathrm{C}$. CP14 (1 $\mu \mathrm{g} /$ well) was coated for $48 \mathrm{~h}$ at $4{ }^{\circ} \mathrm{C}$ in $10 \mathrm{mM}$ PBS, pH $7.3(100 \mu \mathrm{L} /$ well $)$. Plates were then washed with PBS $0.05 \%$ Tween $20(3 \times 200 \mu \mathrm{L})$, saturated using PBS containing $10 \%$ skimmed milk at $37{ }^{\circ} \mathrm{C}$ for $2 \mathrm{~h}$, then washed using PBS Tween 20 (PBST, $50 \mathrm{mM}$ Tris, $150 \mathrm{mM} \mathrm{NaCl}, 0,1 \%$ Tween 20) $(3 \times 200 \mu \mathrm{L})$. Series of 
dilution of sera in PBS containing 10\% skimmed milk (100 $\mu \mathrm{L} /$ well), were incubated at $37^{\circ} \mathrm{C}$ for $2 \mathrm{~h}$. Plates were then washed with PBST $(3 \times 200 \mu \mathrm{L})$ and then incubated with goat anti-mouse $\operatorname{IgG}(\mathrm{H}+\mathrm{L})$-horse radish peroxidase-labeled conjugate (CliniSciences) used as secondary $\mathrm{Ab}$ at a dilution of $1 / 6,000$, for $1 \mathrm{~h}$ at $37{ }^{\circ} \mathrm{C}$ and further washed with PBST $(5 \times 200 \mu \mathrm{L})$. The enzyme substrate, o-phenylenediamine dihydrochloride $(100 \mu \mathrm{L}$ at $0.4 \mathrm{mg} \mathrm{mL}-1$ ) in $0.1 \mathrm{M}$ sodium citrate ( $\mathrm{pH} 5.2$ ), containing $0.02 \%$ hydrogen peroxide, was added to each well and the plate incubated for $20 \mathrm{~min}$ at room temperature in the dark. The reaction was terminated by adding $3 \mathrm{M}$ $\mathrm{HCl}(1,000 \mu \mathrm{L}$ per well), and the A492 was read in an Infinite M1000 spectrophotometer (TECAN). The Ab titer was defined as the dilution of immune serum that gave an OD $(405 \mathrm{~nm})$ at least twice that observed with preimmune serum.

\section{Results and discussion}

\section{Conjugate synthesis}

We envisioned to use synthetic 2-aminoethyl ( $\beta$-D-galactopyranosyl)-( $1 \rightarrow 4)-(\beta$-D-galactopyranosyl)-( $1 \rightarrow 6)-[(\beta-$ D-galactopyranosyl)-(1 $\rightarrow 4)]$-2-deoxy-2-acetamido- $\beta$-D-glucopyranoside tetrasaccharide (Pn14TS, Scheme 1) as a model carbohydrate antigen to test Dd as a carrier protein in glycoconjugate vaccine formulation. Indeed, Pn14TS is readily accessible by chemical synthesis from common sugars. Moreover, this tetrasaccharide was previously selected by Polonskaya et al. to develop Q $\beta$-based VLP glycoconjugates [17] and Pn14TS-based semi-synthetic glyconjugates proved to be immunogen in mice in several laboratories including ours [28],[29],[25]. Both carbohydrate antigen size/length and carbohydrate antigen/carrier protein ratio impact the anti-carbohydrate antigen response. Increasing the ratio usually counteracts the lower immunogenicity associated with short carbohydrate antigens compared to longer ones [30],[31]. This is also observed for Pn14TSconjugates [32],[9]. Considering the huge molecular weight difference between Pn14TS (<1000 Da) and Dd $(3,800,000 \mathrm{Da})$, we therefore elected to use homobifunctional glutaraldehyde as crosslinking reagent to attach the tetrasaccharide to the protein since we experienced that the actual loading was superior to other conjugation techniques likewise thiol/maleimide conjugation [33].

Pn14TS was obtained from a 2-azidoethyl-functionalized peracetylated precursor [25] in two steps comprising the nickel boride reduction [34] of the azide into amine followed by Zemplén deprotection of the acetates (Scheme 1). Then, Pn14TS was first reacted shortly with glutaraldehyde, and the resulting mixture further condensed with Dd at a 400:1 tetrasaccharide protein ratio, followed by sodium borohydride reduction of the imine linkages into amines to stabilize the conjugates.

\section{Conjugate characterization}


After dialysis the conjugates were analyzed for their protein and sugar contents according to colorimetric

181 Bradford and anthrone/sulfuric acid method, respectively. Protein recovery was estimated equal to $70 \%$ while total sugar molar content was 180 times that of the protein. The MALDI-TOF mass spectrum of the conjugate preparation was next compared with that of Dd to determine the extent of derivatization (Fig. 1). The analysis can be performed on the penton base, the monomeric unit which composes Dd. The molecular weight of the penton base and the conjugated penton base differs from 2,086 mass unit which corresponds to 2.5 conjugated tetrasaccharides on average. Consequently a loading of 150 Pn14TS was achieved per particle on average. The penton base contains 25 lysine residues within its sequence among with K152, K166, K305, K306, K348, K349, K358, K361 and K390 appear readily surface accessible for conjugation as determined from adenovirus dodecahedron X-ray crystallography structure [35],[36]. Vicinicity of most accessible lysine side-chain amines might contribute to mitigate the number of conjugated Pn14TS due to steric hindrance caused by the attachment of a first tetrasaccharide unit (Fig. 2).

The assembly status of Dd and Pn14TS-Dd was analyzed by electron microscopy (EM) prior to immunization (Fig. 3). Both Dd (Fig. 3a) and Pn14TS-Dd (Fig. 3b) formulations contain homogeneous particles meaning that neither sample preparation nor conjugation affect the particle assembly. Alternatively, in order to evaluate whether the nanoparticle nature of the glycoconjugate influences the level or the nature of the immune response, a batch of the conjugate was freeze-dried in absence of cryo-protectant and then reformulated in PBS. As seen in Fig. 3c, dodecahedra were not detected by EM suggesting that the freeze-drying step has led to the complete disruption of the complexes as expected. Finally, antigenicity of Pn14TS-Dd was assessed by Western-Blot experiment using polyclonal Abs contained in a hyperimmune mouse sera raised against a Pn14TS-based glycoconjugate [25] and goat anti-mouse $\operatorname{IgG}(\mathrm{H}+\mathrm{L})$-Alexa680-labeled conjugate as secondary Ab. Neither conjugation and purification steps interfered with accessibility of Pn14TS which retained its antigenicity in comparison with purified serotype 14 capsular polysaccharide used as a positive control and PBS or native Dd (negative controls) (data not shown).

\section{Immunization of mice and humoral response evaluation}

Groups of C57BL/6 mice were immunized thrice s.c. at two weeks interval with Dd, the Pn14TS-Dd conjugate in both native (particle), and disassembled form and PBS as a negative control. Antibody responses against purified S. pneumoniae serotype 14 polysaccharide capsule $(\mathrm{CP})$ and Dd was assessed one week after the second (D21) and the third (D35), immunizations. 
The titers of anti-Dd IgG were first measured using Dd as a coating antigen (Fig. 4A and 4B). Dd as well as both formulations of Pn14TS conjugates were able to induce anti-Dd IgGs while such response was not observed for PBS control. High level of Abs was detected after the second immunization (Day 28) (Fig. 4A) and maintained after the boost (Day 35), in the group of mice immunized with disassembled Pn14TS-Dd and increased for the groups immunized with either Dd or Pn14TS-Dd. Observed increase was only statistically significant $(\mathrm{P}<0.05)$, between the group immunized with Dd and that immunized with disassembled Pn14TS-Dd. The later conjugate corresponds to a conjugate whereby the tetrasaccharide has been conjugated to free adenoviral type 3 penton base. Recombinant penton base proteins are easily expressed in Escherichia coli and have sometimes been proposed as efficient surrogates for live-attenuated adenoviral vaccine [37]. However, true comparison with dodecahedra has not yet been reported to our knowledge. Of note, penton bases have been shown to be 1000 times less efficient than dodecahedra to infect cells [38], a feature which might explain observed differences in the IgG response between the two groups. In the present study, IgGs titers induced in mice by the Pn14TS-Dd conjugate is comprised between those induced by Dd and those induced by disassembled Pn14TS-Dd used as immunogens. Therefore, one cannot exclude that important B epitopes are masked by the attached tetrasaccharide, despite the low extent of derivatization and/or a response against unraveled ones, not detected by native Dd used as the coated antigen for ELISA assays.

We next turned our attention to the anti-CP response. The $\operatorname{IgG}$ response raised against $\mathrm{CP}$ by the conjugates was very low and not significant compared to Dd or the negative control group (data not shown) [39]. This response was equally low when we used Pn14TS as the coating antigen suggesting that the observed results were not due to a lack of recognition of CP by anti-Pn14TS Abs. Anti-CP IgM response was also determined after the second and the third immunizations. Significant titers of anti-CP IgM Abs could be measured in the sera of mice immunized with either native or disassembled Pn14TS-Dd in comparison with both Dd and PBS for which no anti-CP response was observed (Fig. 4C). Anti-CP response was however absent in third sera (data not shown). Since the IgM response is not sustained between the second and the third immunization, this hyporesponsiveness, in particular the absence of IgM-to-IgG switch, unlikely derived from the presence of free Pn14TS (16\%), which contaminates the formulations as suggested by the comparison of total sugar versus covalently bound sugar content as determined by colorimetric method and mass spectrometry (vide supra). Along this line, to our knowledge, acceptable amount of free polysaccharide present in polysaccharide-protein conjugate vaccines is $20 \%$ of the total carbohydrate antigen content. Moreover suppression of the T-dependent immune response could not be determined for pneumococcal conjugates, which typically contain $10 \%$ of free 
polysaccharide [40],[41]. On the other hand, Dd MHCII epitopes are functional since a strong anti-carrier IgG response is observed (Fig. 4A). This observation suggests that anti-CP IgG is delayed (in their study Polonskaya et al. carried out two immunizations at 6 weeks interval and analyzed the sera at weeks 5 and 8 [17] while we carried out analyses at weeks 3 and 5), that Dd B cell epitopes are immunodominant compared to Pn14TS antigenic determinants, that conjugation took place too far from Dd MHC II epitopes to benefit of T cell help or to recruit Tcarb [42],[9],[3] or that Pn14TS loading or density is too weak [13]. Anti-Pn14TS response strongly depends on both dose and Pn14TS/carrier protein ratio. For example, it has been reported that levels of antiPn14TS and anti-CRM ${ }_{197}$ (used as a carrier) IgG correlate positively and negatively, respectively, with Pn14TS loading at a $2.5 \mu \mathrm{g}$ Pn14TS/mouse/dose [32]. Significant IgG level were raised against $\mathrm{CRM}_{197}$ and, conversely moderate anti-Pn14TS IgG response, even at a 5:1 Pn14TS/CRM 197 ratio whilst $\mathrm{CRM}_{197}$ is known to induce low anti-carrier Abs and is therefore considered as the best protein carrier for carbohydrate antigens to date [43]. This situation should be stressed herein whereby Pn14TS has been administered at a $1.9 \mu \mathrm{g}$ dose at a 2.5:1 Pn14TS/Penton base (which has same molecular weight as $\mathrm{CRM}_{197}$ ) molar ratio or at a 150:1 Pn14TS/Dd molar ratio which corresponds to a 1.9/64 $\mu \mathrm{g}$ ratio ( 0.03 weight ratio). In the past, $\operatorname{IgG}$ responses have been observed at Pn14TS dose of $1.1 \mu \mathrm{g}$ [29] and we obtained a significant response using as less as $0.5 \mu \mathrm{g}$ of Pn14TS with pneumococcal surface protein A as the carrier protein (unpublished results) but at higher 5.4:1 Pn14Ts/carrier protein ratio. In their study, Polonskaya et al. used a different VLP carrier, bacteriophage Q $\beta$ [17]. Mice were immunized with $100 \mu \mathrm{g}$ of conjugates bearing on average 20, 40, 80 or 200 Pn14TS per particle i.e. roughly 1.4, 2.7, 5.4 and 13.4 $\mu \mathrm{g}$ of Pn14TS, respectively. The herein described Pn14TS-Dd conjugate is similar to the 20:1 (0.01 weight ratio) and 40:1 (0.03 weight ratio) Pn14TS-Q $\beta$ conjugates. Noticeably, anti-Pn14TS IgG response was not elicited by the former conjugate while the later elicited some variability in both the primary and the secondary responses, observations which are in agreement with our own results. It is thus possible that the threshold required to induce a strong anti-Pn14TS was not reached by Pn14TS-Dd.

\section{Conclusion}

263 Glycoconjugate vaccines are very efficient and well tolerated in humans. Future glycoconjugate vaccine improvements consist in increasing the number of carrier protein available to avoid carrier epitope suppression phenomena as well as in mobilizing broader immune cell population subsets such as $\mathrm{T}$ follicular helper-like cells [44]. For example, it has been shown that recruitment of $\mathrm{T}$ follicular helper cells strongly correlates with enhanced oposonophagocytic antibody response induced by conjugated pneumococcal vaccines in young 
cells among the later population is a valuable strategy for the generation of durable antibody responses to optimize current glycoconjugate vaccines [45]. Virus-like nanoparticles, due to their large surface area to volume ratio and mutivalency which resembles the natural features of viruses can fulfil these goals: B cells specific for $\mathrm{Q} \beta$-derived VLP used as antigen are sufficient to induce $\mathrm{T}$ follicular helper cell development in absence of 273 antigen presenting cells [46]. Therefore, VLPs are expected to favor follicular lymph nodes processing of glycoconjugates. Along this line, adenoviral type $3 \mathrm{Dd}$ has been herein proposed as a novel nanoparticle carrier for glycoconjugate vaccine using a synthetic tetrasaccharide mimic of the $S$. pneumoniae serotype 14 capsular polysaccharide. Resulting VLP-based glycoconjugate proved robust to sequential synthetic and purification steps and easily characterized. Noticeably, conjugation of the synthetic tetrasaccharide to Dd particles was carried out without impacting their assembly. Glutaraldehyde was selected as bifunctional immuno-silent linker for the conjugation step as it was anticipated that a high carbohydrate antigen/carrier ratio would be necessary to induce an anti-carbohydrate antigen response. Despite a 150:1 ratio, a weak, early anti-carbohydrate antigen IgM and no IgG response have been determined in mice following s.c. immunizations. Contrasting with these observations the Dd carrier was strongly immunogenic and induced an anti-Dd IgG response. Further studies will thus be needed to validate adenoviral type $3 \mathrm{Dd}$ as a carrier. Efforts will focus on increasing length of the linker to make the carbohydrate antigen more accessible to the immune system, or increasing the length of carbohydrate antigen itself and reaching higher extent of derivatization while exploiting its tolerance towards sequence engineering, the opportunity to encapsulate molecules e.g. Toll-like receptor agonists and exploring mucosal administration, the natural route of infection of adenoviruses,

\section{Acknowledgments}

MP acknowledges doctoral fellowship from the European Commission, Education, Audiovisual and Culture Executive Agency (EACEA), under the Erasmus Mundus program, NanoFar. NR thanks the Région Pays de la Loire, International Strategy Program "NanoFar"” for a travel grant. The authors gratefully acknowledge Anthony Piticco for its technical assistance, Dorian Caudal and Aude Lafoux from platform Therassey (Nantes) for animal experiments and Dr Jadwiga Chroboczek for helpful discussion. This work used the EM facilities at the Grenoble Instruct-ERIC Center (ISBG; UMS 3518 CNRS CEA-UGA-EMBL) with support from the French Infrastructure for Integrated Structural Biology (FRISBI; ANR-10-INSB-05-02) and GRAL, a project of the University Grenoble Alpes graduate school (Ecoles Universitaires de Recherche) CBH-EUR-GS (ANR-17EURE-0003) within the Grenoble Partnership for Structural Biology. The IBS Electron Microscope facility is supported by the Auvergne Rhône-Alpes Region, the Fonds Feder, the Fondation pour la Recherche Médicale 
and GIS-IBiSA. Finally, We also thank the mass spectrometry core facility of CRNH for exact mass

determination.

\section{Compliance with ethical standards}

Conflicts of interest The authors declare that they have no conflicts of interest.

Ethical approval The animal study was reviewed and approved by ethical permit number from Comité

d'Ethique en Expérimentation Animale (CEEA): 7897.

Data availability The datasets generated during and/or analysed during the current study are available from the corresponding author on reasonable request.

\section{References}

[1] M. Heidelberger et O. T. Avery, « THE SOLUBLE SPECIFIC SUBSTANCE OF PNEUMOCOCCUS », J Exp Med, vol. 38, no 1, p. 73-79, juill. 1923, doi: 10.1084/jem.38.1.73.

[2] R. Rappuoli, « Glycoconjugate vaccines: Principles and mechanisms », Sci Transl Med, vol. 10, nº 456, 29 2018, doi: 10.1126/scitranslmed.aat4615.

[3] X. Sun, G. Stefanetti, F. Berti, et D. L. Kasper, « Polysaccharide structure dictates mechanism of adaptive immune response to glycoconjugate vaccines », Proc Natl Acad Sci U S A, vol. 116, n 1, p. 193-198, 02 2019, doi: 10.1073/pnas.1816401115.

[4] M. Bröker, F. Berti, J. Schneider, et I. Vojtek, « Polysaccharide conjugate vaccine protein carriers as a "neglected valency" - Potential and limitations », Vaccine, vol. 35, n 25, p. 3286-3294, 05 2017, doi: 10.1016/j.vaccine.2017.04.078.

[5] F. Micoli, R. Adamo, et P. Costantino, « Protein Carriers for Glycoconjugate Vaccines: History, Selection Criteria, Characterization and New Trends », Molecules, vol. 23, $\mathrm{n}^{\circ}$ 6, juin 2018, doi: 10.3390/molecules23061451.

[6] V. B. Pinto, R. Burden, A. Wagner, E. E. Moran, et C.-H. Lee, « The development of an experimental multiple serogroups vaccine for Neisseria meningitidis », PLoS One, vol. 8, n 11, p. e79304, 2013, doi: 10.1371/journal.pone.0079304.

[7] C. Grandjean, T. K. Wade, D. Ropartz, L. Ernst, et W. F. Wade, « Acid-detoxified Inaba lipopolysaccharide (pmLPS) is a superior cholera conjugate vaccine immunogen than hydrazine-detoxified lipopolysaccharide and induces vibriocidal and protective antibodies », Pathog Dis, vol. 67, n 2, p. 136-158, mars 2013, doi: 10.1111/2049-632X.12022.

[8] M. C. Woodruff, E. H. Kim, W. Luo, et B. Pulendran, « B Cell Competition for Restricted T Cell Help Suppresses Rare-Epitope Responses », Cell Rep, vol. 25, n 2, p. 321-327.e3, oct. 2018, doi: 10.1016/j.celrep.2018.09.029.

[9] A. Pillot et al., «Site-Specific Conjugation for Fully Controlled Glycoconjugate Vaccine Preparation », Front Chem, vol. 7, p. 726, 2019, doi: 10.3389/fchem.2019.00726.

[10] K. T. Gause, A. K. Wheatley, J. Cui, Y. Yan, S. J. Kent, et F. Caruso, « Immunological Principles Guiding the Rational Design of Particles for Vaccine Delivery », ACS Nano, vol. 11, nº 1, p. 54-68, janv. 2017, doi: 10.1021/acsnano.6b07343.

[11] V. Cimica et J. M. Galarza, « Adjuvant formulations for virus-like particle (VLP) based vaccines », Clin Immunol, vol. 183, p. 99-108, 2017, doi: 10.1016/j.clim.2017.08.004.

[12] D. Yan, Y.-Q. Wei, H.-C. Guo, et S.-Q. Sun, « The application of virus-like particles as vaccines and biological vehicles », Appl Microbiol Biotechnol, vol. 99, n 24, p. 10415-10432, déc. 2015, doi: 10.1007/s00253-015-7000-8.

[13] J. Marcandalli et al., «Induction of Potent Neutralizing Antibody Responses by a Designed Protein Nanoparticle Vaccine for Respiratory Syncytial Virus », Cell, vol. 176, nº 6, p. 1420-1431.e17, mars 2019, doi: 10.1016/j.cell.2019.01.046.

[14] A. E. Powell et al., « A single immunization with spike-functionalized ferritin vaccines elicits neutralizing antibody responses against SARS-CoV-2 in mice », ACS Cent Sci. 2021 Jan 27;7(1):183-199. doi: 10.1021/acscentsci.0c01405

[15] S. Sungsuwan, X. Wu, et X. Huang, « Evaluation of Virus-Like Particle-Based Tumor-Associated Carbohydrate Immunogen in a Mouse Tumor Model », Methods Enzymol, vol. 597, p. 359-376, 2017, doi: 10.1016/bs.mie.2017.06.030. 
[16] R. D. Astronomo et al., « Defining criteria for oligomannose immunogens for HIV using icosahedral virus capsid scaffolds », Chem Biol, vol. 17, no 4, p. 357-370, avr. 2010, doi: 10.1016/j.chembiol.2010.03.012.

[17] Z. Polonskaya et al., « T cells control the generation of nanomolar-affinity anti-glycan antibodies », J Clin Invest, vol. 127, $\mathrm{n}^{\circ}$ 4, p. 1491-1504, avr. 2017, doi: 10.1172/JCI91192.

[18] P. Fender, R. W. Ruigrok, E. Gout, S. Buffet, et J. Chroboczek, « Adenovirus dodecahedron, a new vector for human gene transfer », Nat Biotechnol, vol. 15, no 1, p. 52-56, janv. 1997, doi: 10.1038/nbt0197-52.

[19] R. R. Vivès, H. Lortat-Jacob, J. Chroboczek, et P. Fender, « Heparan sulfate proteoglycan mediates the selective attachment and internalization of serotype 3 human adenovirus dodecahedron », Virology, vol. 321, nº 2, p. 332-340, avr. 2004, doi: 10.1016/j.virol.2004.01.015.

[20] P. Fender, G. Schoehn, F. Perron-Sierra, G. C. Tucker, et H. Lortat-Jacob, « Adenovirus dodecahedron cell attachment and entry are mediated by heparan sulfate and integrins and vary along the cell cycle », Virology, vol. 371, no 1, p. 155-164, févr. 2008, doi: 10.1016/j.virol.2007.09.026.

[21] A. Naskalska, E. Szolajska, I. Andreev, M. Podsiadla, et J. Chroboczek, « Towards a novel influenza vaccine: engineering of hemagglutinin on a platform of adenovirus dodecahedron », BMC Biotechnol, vol. 13, p. 50, juin 2013, doi: 10.1186/1472-6750-13-50.

[22] I. Szurgot et al., « Self-adjuvanting influenza candidate vaccine presenting epitopes for cell-mediated immunity on a proteinaceous multivalent nanoplatform », Vaccine, vol. 31, nº 40, p. 4338-4346, sept. 2013, doi: 10.1016/j.vaccine.2013.07.021.

[23] «Synthetic self-assembling ADDomer platform for highly efficient vaccination by genetically encoded multiepitope display - PubMed». https://pubmed.ncbi.nlm.nih.gov/31620562/ (consulté le déc. 16, 2020).

[24] I. Szurgot, M. Jedynak, M. Podsiadla-Bialoskorska, J. Piwowarski, E. Szolajska, et J. Chroboczek, «Adenovirus Dodecahedron, a VLP, Can be Purified by Size Exclusion Chromatography Instead of TimeConsuming Sucrose Density Gradient Centrifugation », Mol Biotechnol, vol. 57, $\mathrm{n}^{\circ}$ 6, p. 565-573, juin 2015, doi: 10.1007/s12033-015-9850-9.

[25] M. Prasanna et al., « Semisynthetic glycoconjugate based on dual role protein/PsaA as a pneumococcal vaccine », Eur J Pharm Sci, vol. 129, p. 31-41, mars 2019, doi: 10.1016/j.ejps.2018.12.013.

[26] D. Herbert, P. J. Phipps, et R. E. Strange, « Chapter III Chemical Analysis of Microbial Cells », in Methods in Microbiology, vol. 5, J. R. Norris et D. W. Ribbons, Éd. Academic Press, 1971, p. 209-344.

[27] C. Grandjean, A. Boutonnier, B. Dassy, J.-M. Fournier, et L. A. Mulard, «Investigation towards bivalent chemically defined glycoconjugate immunogens prepared from acid-detoxified lipopolysaccharide of Vibrio cholerae O1, serotype Inaba », Glycoconj J, vol. 26, n 1 , p. 41-55, janv. 2009, doi: 10.1007/s10719-008-9160-6.

[28] D. Safari et al., «Identification of the smallest structure capable of evoking opsonophagocytic antibodies against Streptococcus pneumoniae type $14 »$, Infect Immun, vol. 76, n 10, p. 4615-4623, oct. 2008, doi: 10.1128/IAI.00472-08.

[29] E. A. Kurbatova et al., « Neoglycoconjugate of Tetrasaccharide Representing One Repeating Unit of the Streptococcus pneumoniae Type 14 Capsular Polysaccharide Induces the Production of Opsonizing IgG1 Antibodies and Possesses the Highest Protective Activity As Compared to Hexa- and Octasaccharide Conjugates », Front Immunol, vol. 8, p. 659, 2017, doi: 10.3389/fimmu.2017.00659.

[30] V. Pozsgay, C. Chu, L. Pannell, J. Wolfe, J. B. Robbins, et R. Schneerson, « Protein conjugates of synthetic saccharides elicit higher levels of serum IgG lipopolysaccharide antibodies in mice than do those of the O-specific polysaccharide from Shigella dysenteriae type 1 », Proc Natl Acad Sci U S A, vol. 96, ${ }^{\circ}$ 9, p. 5194-5197, avr. 1999, doi: 10.1073/pnas.96.9.5194.

[31] F. Carboni et al., «Evaluation of Immune Responses to Group B Streptococcus Type III Oligosaccharides Containing a Minimal Protective Epitope », J Infect Dis, vol. 221, nº 6, p. 943-947, mars 2020, doi: 10.1093/infdis/jiz551.

[32] F. Mawas, J. Niggemann, C. Jones, M. J. Corbel, J. P. Kamerling, et J. F. G. Vliegenthart, «Immunogenicity in a mouse model of a conjugate vaccine made with a synthetic single repeating unit of type 14 pneumococcal polysaccharide coupled to CRM197 », Infect Immun, vol. 70, n 9, p. 5107-5114, sept. 2002, doi: 10.1128/iai.70.9.5107-5114.2002.

[33] O. Milhomme et al., « Synthesis and immunochemical evaluation of a non-methylated disaccharide analogue of the anthrax tetrasaccharide », $\operatorname{Org}$ Biomol Chem, vol. 10, n 42, p. 8524-8532, nov. 2012, doi: $10.1039 / \mathrm{c} 2 \mathrm{ob} 26131 \mathrm{f}$.

[34] J. M. Khurana et A. Gogia, «Synthetically Useful Reactions with Nickel Boride. a Review », Organic Preparations and Procedures International, vol. 29, n 1, p. 1-32, févr. 1997, doi: 10.1080/00304949709355171.

[35] E. F. Pettersen et al., «UCSF Chimera--a visualization system for exploratory research and analysis », $J$ Comput Chem, vol. 25, n 13, p. 1605-1612, oct. 2004, doi: 10.1002/jcc. 20084.

[36] E. Szolajska et al., «The structural basis for the integrity of adenovirus Ad3 dodecahedron », PLoS One, vol. 7, no 9, p. e46075, 2012, doi: 10.1371/journal.pone.0046075. 


\section{FIGURE LEGENDS}

443 Scheme 1 Synthesis of the conjugates. Preparation of Pn14TS from peracetylated precursor followed by conjugation with Dd (represented using PyMol from pdb structure 2C9G [47])using glutaraldehyde to give Pn14TS-Dd. copies of penton base protein make up $1 \mathrm{Dd}$.

Figure 2 Lysine residues (salmon) with amine side chain groups (green) exposed on the surface of the Dd context of whole dodecahedron (gray) (b), and dodecahedron (c). The K337 and K339 are present in the part of 
457 Figure 3 Negative-stain electron microscopy of Dd (a) Pn14TS-Dd conjugate (b) and disassembled Pn14TS-Dd conjugate (c). Stain Acetate d'uranyle (AcUr) $\mathrm{UO}_{2}\left(\mathrm{CH}_{3} \mathrm{COO}\right)_{2} \cdot 2 \mathrm{H}_{2} \mathrm{O}$ at $2 \%$ in distilled water $(\mathrm{pH} 4,2-4,5)$ Magnification $\times 23,000$; bar represents $100 \mathrm{~nm}$.

Figure 4 Titers of anti-Dd (coated on microtiter plates) IgG Abs of mice immunized with Dd, Pn14TS-Dd, disassembled Pn14TS-Dd and PBS after the second (a $\underline{A} A)$ and the third immunization (b-B); Titers of anti-CP (coated on microtiter plates) IgM Abs of mice immunized with Dd, Pn14TS-Dd, disassembled Pn14TS-Dd and PBS after the second immunization (cE). The serum samples data presented as geometric mean titer of five mice
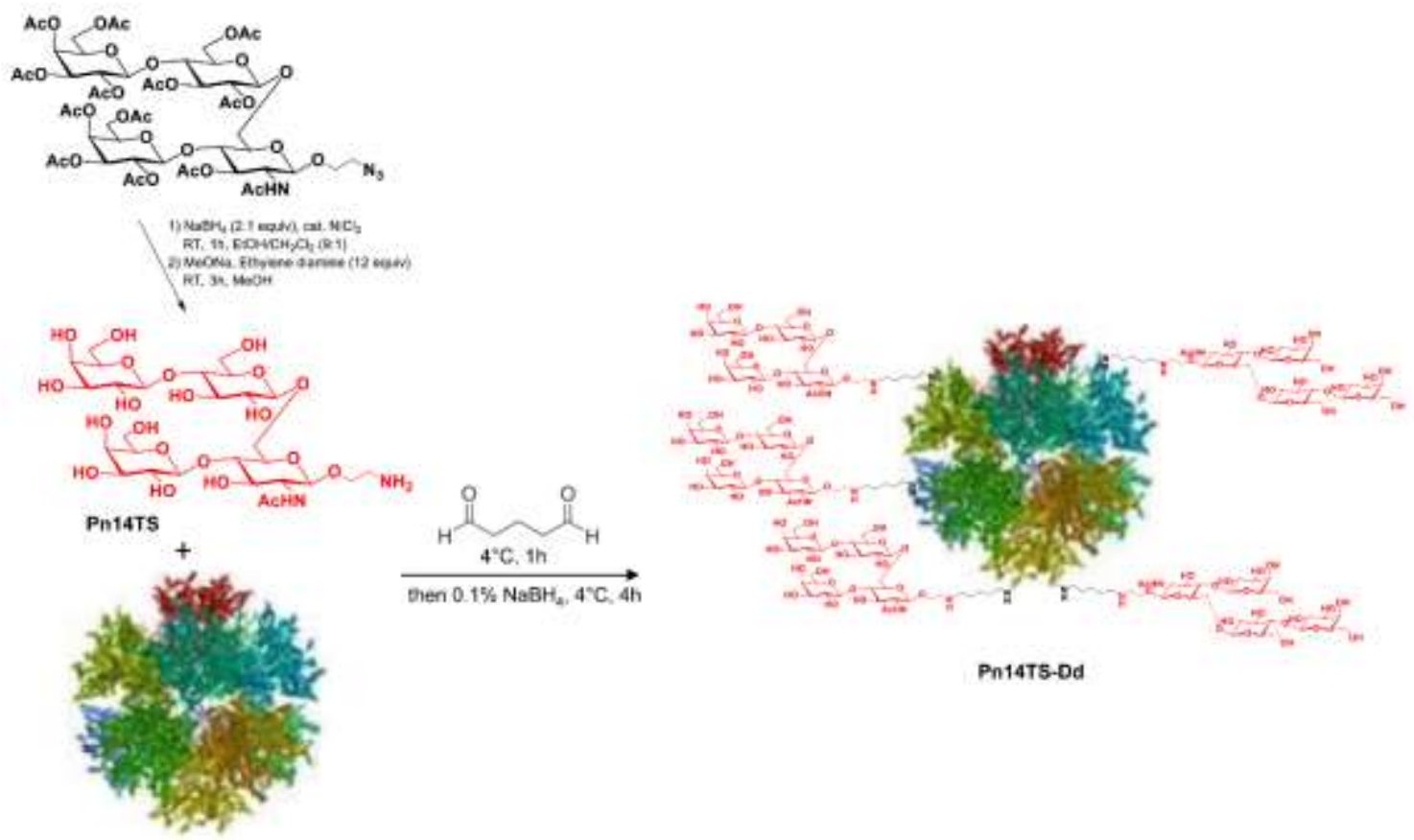

\section{Scheme 1}




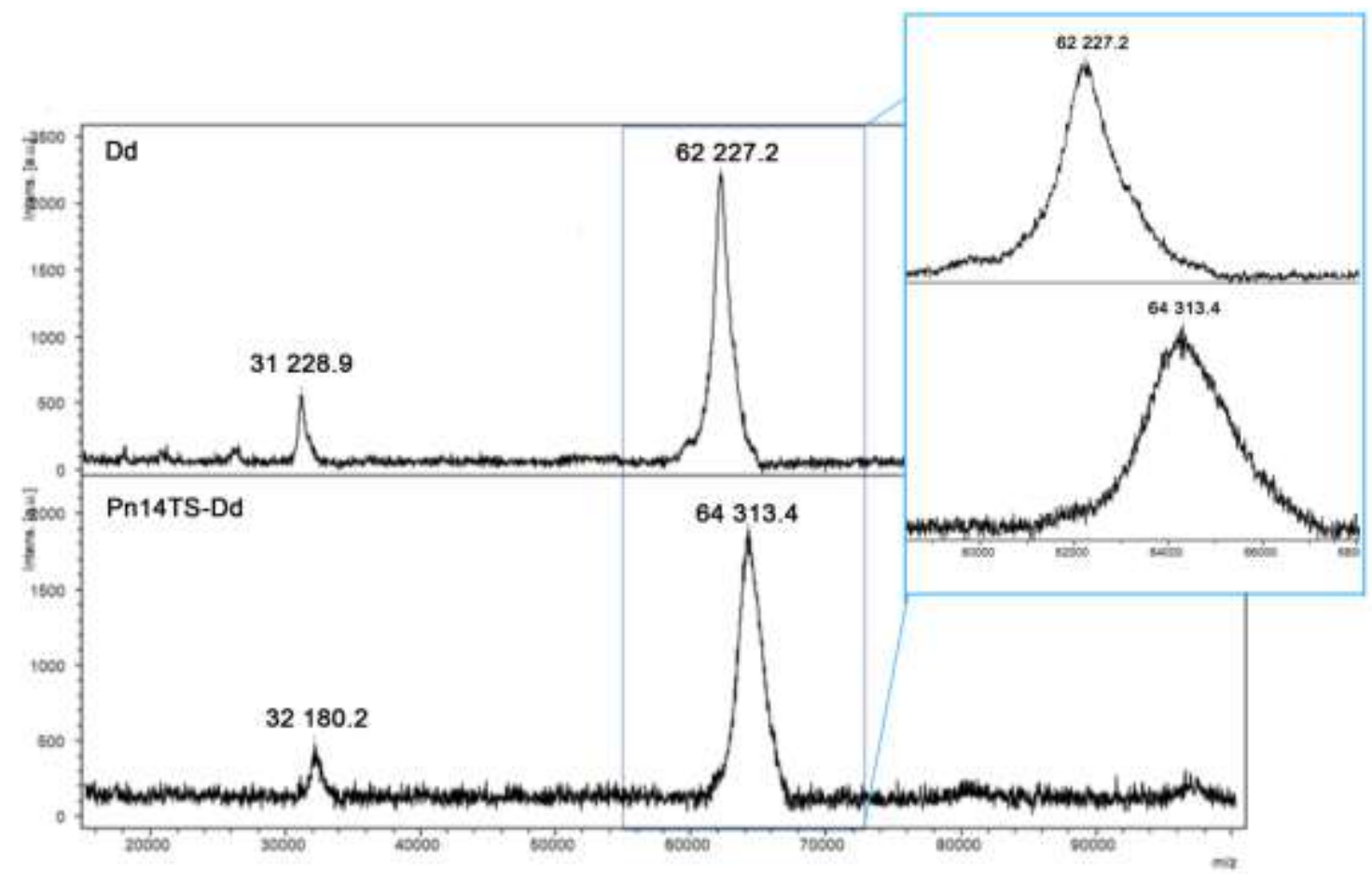

472

$473 \quad$ Figure 1 

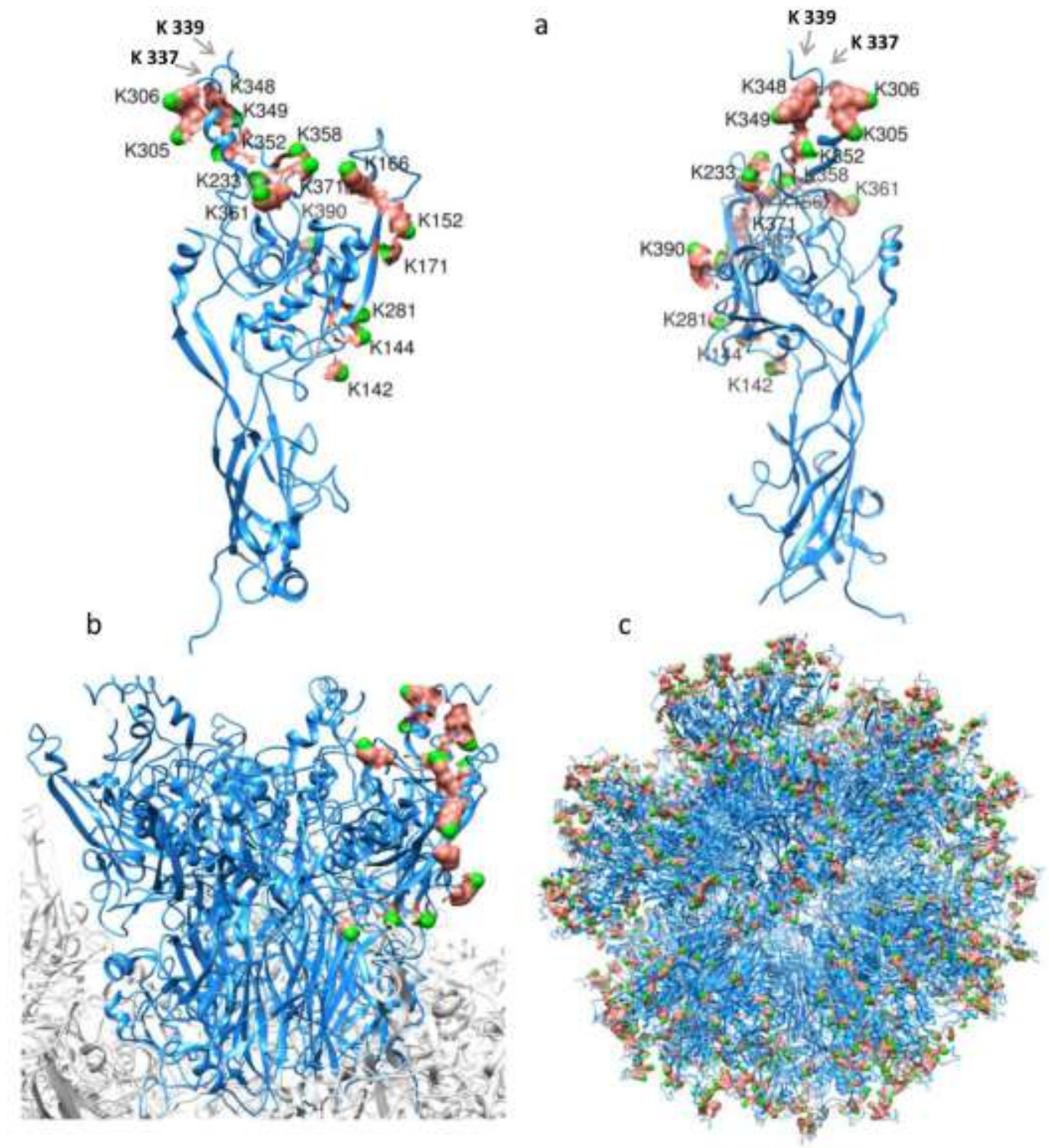

474

$475 \quad$ Figure 2 

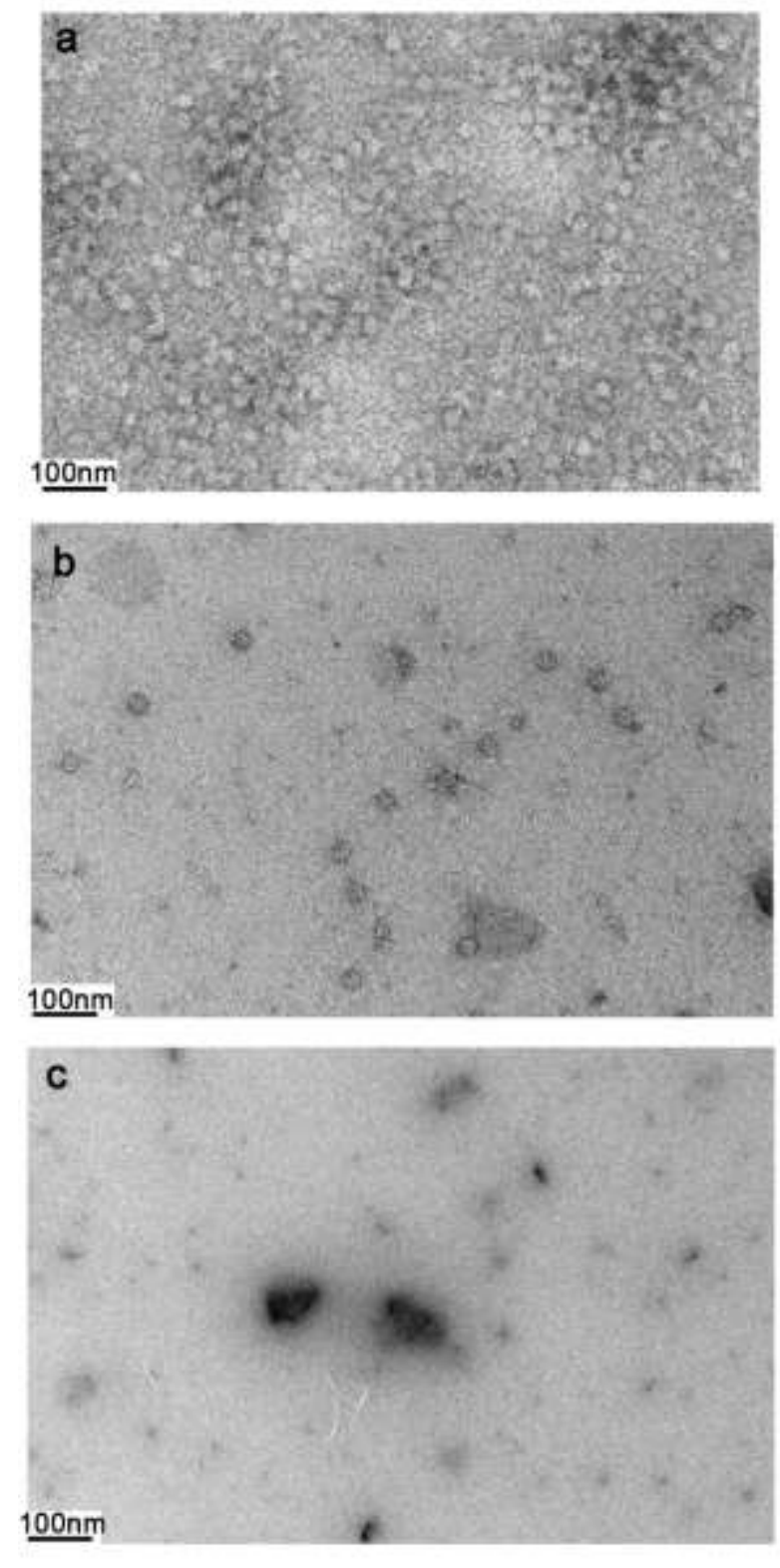

$477 \quad$ Figure 3 

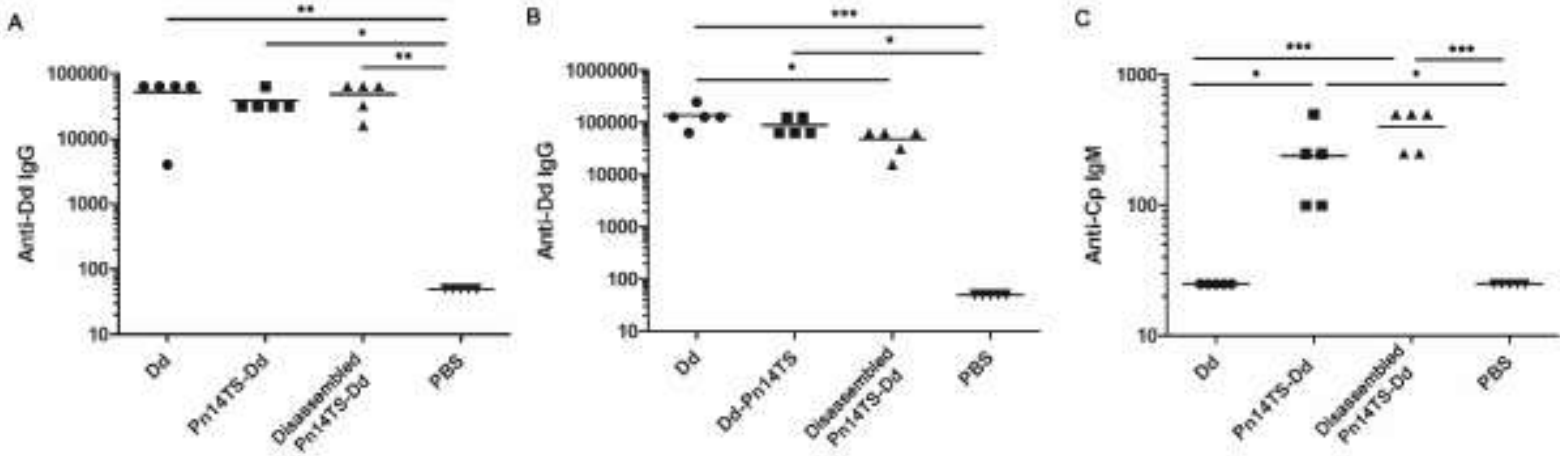

$479 \quad$ Figure 4 